\title{
Evaluation of Low Trace DNA Recovery Techniques from Ridged Surfaces
}

Graham Williams*, Manohar Pandre, Waseeh Ahmed, Emma Beasley, Emma Omelia, Damian World and Holly Yu

Forensic Biology Group, School of Applied Sciences, University of Huddersfield, Huddersfield, UK

\begin{abstract}
The first step in the DNA profiling process is the recovery of DNA from the crime scene or item. Such surfaces can be varying with absorbent and non-absorbent surfaces. Ridged surfaces, such as those encountered on bottletops or firearms, are also common. Although low trace DNA or "touch DNA" is problematic in forensic casework, ridged surfaces should be a more effective surface for the recovery of such DNA due their abrasive nature. The aim of this study was to evaluate six recovery techniques; single wet swab, dry-wet double swab, wet-dry double swab, flocked swab, PCR square, and tape lifts. 36 falcon tubes with screw top lids were sterilised before DNA was deposited on the screw-top lids. Each of the recovery techniques were then utilised on 6 screw-top lids. All recovery media then underwent standard DNA extraction prior to DNA quantification by UV/Vis spectroscopy and quantitative PCR. The data indicated that the tape lifts recovered significantly more DNA from the ridged surface than the other techniques. There was no significant difference between the remaining 5 techniques, although on average, flocked swabs recovered the least amount. This suggested that the success in recovery of DNA is not down to the particular technique used, but down to the competence of the individual examiner and the amount of DNA deposited onto the surface.
\end{abstract}

Keywords: Forensic genetics; DNA recovery; DNA quantification; Swabs; Flocked swabs; Tape lift; Ridged surfaces

\section{Introduction}

One of the most important steps during the DNA profiling process is the recovery of DNA. Much research is carried out on the analysis and interpretation of DNA; however, no amount of increasingly sensitive amplification and analysis will overcome the issue of poor recovery.

Different surfaces do require different recovery techniques and research has been carried out in these areas, such as the use of tape lifts to recover DNA from clothing [1] and from fingerprints [2]. Such methods have included the use of various swabbing techniques, including the use of flocked swabs.

The aim of this study was to compare various sampling techniques in order to identify the most effective DNA recovery method for use on ridged surfaces, such as that encountered on bottle tops and firearms.

\section{Method and Materials}

\section{Sample preparation}

Thirty-six $50 \mathrm{ml}$ falcon tubes with screw top lids were sterilised by Microsol and medi-wiped and then left to air dry under a UV light. Volunteers then unscrewed and replaced all of the screw top lids with bare hands. These screw top lids had ridged surfaces, similar to that of the common bottle screw tops. The falcon tubes were then split in six groups of six for sample recovery. Negative controls were included.

\section{Sample recovery}

\section{Six different sampling techniques were used.}

Single swabbing technique: This technique is a standard technique in which a sterile swab is moistened with sterile $\mathrm{H}_{2} \mathrm{O}$ and then rubbed over the surface which is thought to hold DNA. This swab then proceeds to the extraction phase [3]

Wet/Dry (WD) Double swabbing technique: WD or Wet and then Dry double swabbing technique is an expansion of the single swab technique. After the wet or damp swabbing has been done, a fresh sterile swab is then used to swab over the damp surface. It is thought that this second swab would recover any residues of DNA left behind on the damp surface. The swabs are then combined prior to the extraction phase. This technique is generally used on non-absorbent surfaces $[3,4]$.

Dry/Wet (DW) Double swabbing technique: This is the same technique as above, except this time the surface is swabbed with a dry swab and then swabbed again with a wet swab. This technique is generally used on absorbent surfaces, such as clothing, as the wet swab can cause a 'wicking' effect in which the DNA material is drawn down through the fabric away from the surface; therefore making it difficult recover the DNA material. Although the majority of ridged surfaces are not considered to be absorbent, this technique is included for completeness $[3,4]$.

PCR squares: This is a small square of sterile filter paper $\left(\sim 3 \mathrm{~mm}^{2}\right)$. This is moistened with sterile $\mathrm{H}_{2} \mathrm{O}$ and used as a swab. The square is usually manipulated by the tip of a 10 blade scalpel. However, since tool marks on metal or hard surfaces can be easily compromised by fine scratches, a wooden probe is used instead (similar in appearance to a cocktail stick). The PCR square then proceeds onto the extraction phase. The advantage of this technique is that it reduces the amount of substrate containing the DNA and therefore should be more effective upon extraction. Another advantage of this technique is that PCR squares can be manipulated into small spaces and surfaces, such as the magazine release on pistols.

Flocked swabs: Flocked swabs are effectively brushes where each

*Corresponding author: Graham Williams, Forensic Biology Group, School of Applied Sciences, University of Huddersfield, Huddersfield, West Yorkshire, UK, E-mail: graham.williams@hud.ac.uk

Received August 30, 2013; Accepted September 23, 2013; Published September 26, 2013

Citation: Williams G, Pandre M, Ahmed W, Beasley E, Omelia E, et al. (2013) Evaluation of Low Trace DNA Recovery Techniques from Ridged Surfaces. J Forensic Res 4: 199. doi:10.4172/2157-7145.1000199

Copyright: (c) 2013 Williams G, et al. This is an open-access article distributed under the terms of the Creative Commons Attribution License, which permits unrestricted use, distribution, and reproduction in any medium, provided the original author and source are credited. 
of the bristles has an absorbent tip [5]. The theoretical advantages of the flocked swabs are two-fold. Firstly, the bristles can get into smaller spaces and surfaces, in a similar manner as PCR squares. Secondly, normal swabs have an issue in that the DNA material can wick away from the surface of damp swabs as the $\mathrm{H}_{2} \mathrm{O}$ soaks into the swab. This causes problems during the extraction phase as the swab itself is protecting the DNA from the detergent and proteinases. The flocked swabs overcome this by only having absorbent surfaces at the tip of each bristle, thus minimising any wicking effect and increasing the surface area for exposure to the proteinases [6].

Taping: Small sterile strips of adhesive tape (Invitrogen) were applied to the surface. The DNA material should then transfer on to the tape which can then be removed. This piece of tape can then be placed into a microcentrifuge tube for extraction.

\section{DNA extraction}

DNA extraction was carried out using the QIAampDNA Mini kit (Qiagen, UK) as per manufacturer's instructions with the exceptions of some minor modifications for each recovery technique.Single swabs (cotton and flocked) were cut off the stick and placed into a microcentrifuge tube. For the double swabbing techniques, the swabs were placed into the same microcentrifuge tube. The tape lifts were cut into strips and placed into a microcentrifuge tube. The PCR squares were simply placed into the microcentrifuge tube. In all cases, $500 \mu \mathrm{l}$ of phosphate buffered saline was added to the sample. The use of a spin basket (Invitrogen) step was incorporated in order to maximise the DNA yield.

\section{DNA quantitation}

Following extraction, each of the samples were quantified using the NanoVue spectrophotometer (GE Healthcare) and using the Human DNA Quantifiler System (Life Technologies, UK) on the 7500 Fast RealTime PCR Machine (Life Technologies, UK). Significant differences were assessed using Paired Sample T-test with a significance threshold of $<0.05$.

\section{Results}

\section{DNA quantitation results}

The DNA quantitation results indicate that the taping technique recovers more DNA from ridged surfaces than the other techniques. A paired sample T-test showed that the taping technique demonstrates a significant increase in the amount of DNA recovered $(p=<0.05)$. However, there are no significant differences between the amounts of DNA recovered from the other five techniques (Table 1).

The values obtained from conducting UV/Vis Spectrophotometry are higher than those obtained using the Human Quantifiler Kit; this is due to the substantially higher specificity of the Quantifiler kit (Figure 1).

\begin{tabular}{|l|l|l|}
\hline Recovery technique & NanoVue (SD) & Quantifiler (SD) \\
\hline Single swabbing $(n=18)$ & $2.89(1.14)$ & $0.30(0.6)$ \\
\hline WD double swabbing $(n=18)$ & $2.77(1.35)$ & $0.13(0.05)$ \\
\hline DW double swabbing $(n=18)$ & $2.00(2.00)$ & $0.16(0.04)$ \\
\hline PCR squares $(n=18)$ & $2.38(2.20)$ & $0.04(0.025)$ \\
\hline Flocked swabs $(n=18)$ & $1.27(0.98)$ & $0.05(0.0008)$ \\
\hline Taping $(n=18)$ & $4.47(2.48)$ & $0.21(0.1)$ \\
\hline
\end{tabular}

Table 1: Showing the mean quantity $(\mathrm{ng} / \mu \mathrm{l})$ of DNA obtained from a range of DNA recovery techniques. Both NanoVue Spectrophotometry and Quantitative PCR (Quantifiler) data were used. Values shown are $\mathrm{ng} / \mu \mathrm{l}$ with standard deviation in parentheses.

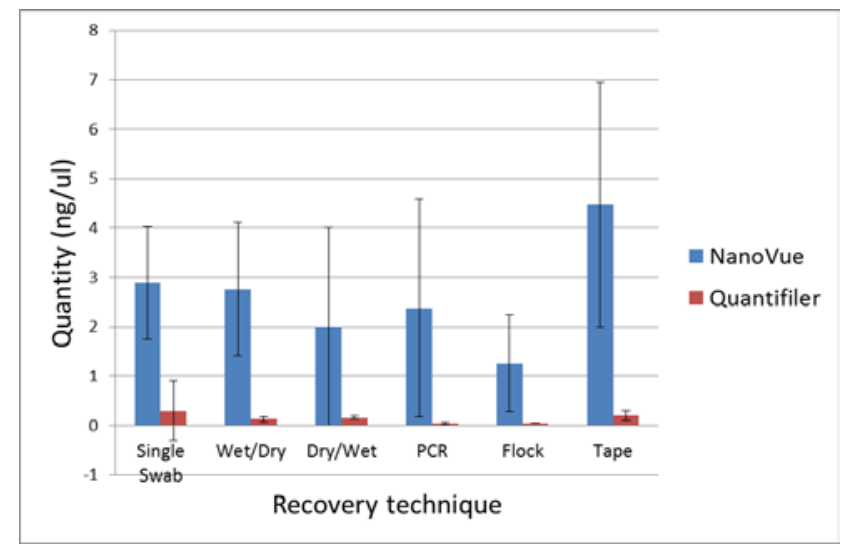

Figure 1: A chart indicates the DNA quantitation values for all six different recovery methods. This data is obtained using the Human DNA Quantification Kit and NanoVue UV-Vis spectroscopy.

\section{Discussion}

The aim of this study was to assess which of the more commonly used DNA recovery techniques is most appropriate for use on ridged surfaces. This was achieved by depositing human DNA on to a series of screw-top tubes and recovery said material using the 6 techniques. After undergoing standard DNA extraction, the amount of DNA was quantified using UV/Vis spectrometry and quantitative PCR (qPCR). Although dependant on the individual laboratory and the STR profiling kit selected, the amount of human DNA required to obtain a full DNA profile is generally between $0.2-0.5 \mathrm{ng}$. Lower amounts can still produce a useful partial DNA profile, albeit with a higher match probability.

The human DNA quantification valuesare considerably lower than this threshold; however, it might still be possible obtain a useful DNA profile. This is expected to a certain extent as the DNA sample in question is from low trace DNA or "touch DNA". However, as the purpose of this study is to evaluate the recovery techniques, it is the amount of DNA that is recovered and subsequently analysed in comparison between the techniques that is of interest.

The tape lift method recovered significantly more DNA $(\mathrm{p}<0.05)$ than the other techniques; thus suggesting that this method should be used for recovering touch DNA from ridged surfaces. There were no significant differences in the amount of DNA recovery between the remaining 5 techniques; although the amount of DNA recovered using the flocked swab was the lowest.

Although there is literature supporting the use of flocked swabs [1], these are limited to post-coital vaginal swabs and therefore do not necessarily relate to touch DNA on ridged surfaces. There is also a study by Hansson et al. investigating DNA recovery techniques from clothing [6] which also considered flocked swabs as well as tape lifts. This study also indicated that tape lifts recovered more DNA from clothing than flocked swabs; thus supporting the findings of this study, albeit on a different surface type.

In considering whether a single swab, double swab or flocked swab is most appropriate, there does not appear to be any preference. This suggests that any perceived preference for a particular method is more down to the individual examiner's competence and the amount of DNA material present on the ridged surface. 
Citation: Williams G, Pandre M, Ahmed W, Beasley E, Omelia E, et al. (2013) Evaluation of Low Trace DNA Recovery Techniques from Ridged Surfaces. J Forensic Res 4: 199. doi:10.4172/2157-7145.1000199

\section{Summary}

In summary, of the 6 recovery techniques evaluated the use of tape lifts appear to be most appropriate for the recovery of low trace DNA from ridged surfaces. All other techniques were not significantly different, suggesting that any particular success in recovery of DNA material is a combination of the amount of DNA present and the examiner's competence, rather than the technique itself.

\section{References}

1. Barash M, Reshef A, Brauner $P(2010)$ The use of adhesive tape for recovery of DNA from crime scene items. J Forensic Sci 55: 1058-1064.
2. Schulz MM, Reichert W (2002) Archived or directly swabbed latent fingerprints as a DNA source for STR typing. Forensic Sci Int 127: 128-130.

3. Castella V, Mangin P (2008) DNA profiling success and relevance of 1739 contact stains from caseworks. Forensic Science International: Genetics Supplement Series 1: 405-407.

4. Pang BC, Cheung BK (2007) Double swab technique for collecting touched evidence. Leg Med (Tokyo) 9: 181-184.

5. Benschop CC, Wiebosch DC, Kloosterman AD, Sijen T (2010) Post-coita vaginal sampling with nylon flocked swabs improves DNA typing. Forensic Sci Int Genet 4: 115-121.

6. Hansson O, Finnebraaten M, Heitmann IK, Ramse M, Bouzqa M (2009) Trace DNA collection--Performance of minitape and three different swabs. Forensic Science International: Genetics Supplement Series 2: 189-190. 